\title{
Fibronectin expression is critical for liver fibrogenesis in vivo and in vitro
}

\author{
XIAO-YA LIU ${ }^{1,2^{*}}$, RUI-XIA LIU $^{1 *}$, FEI HOU ${ }^{1}$, LI-JIAN CUI ${ }^{1}$, CHUN-YUN LI $^{2}$, CHENG CHI $^{2}$, \\ ENTONG YI ${ }^{1}$, YAN WEN ${ }^{1}$ and CHENG-HONG YIN ${ }^{2}$ \\ ${ }^{1}$ Department of Infection, Beijing Friendship Hospital, Capital Medical University, Beijing 100050; \\ ${ }^{2}$ Department of Internal Medicine, Beijing Obstetrics and Gynecology Hospital, \\ Capital Medical University, Beijing 100026, P.R. China
}

Received August 5, 2015; Accepted August 2, 2016

DOI: $10.3892 / \mathrm{mmr} .2016 .5673$

\begin{abstract}
Increased fibronectin (FN) expression has an important role during liver fibrosis. The present study examined FN expression in rats subjected to carbon tetrachloride $\left(\mathrm{CCl}_{4}\right)$-induced liver fibrosis. In addition, the potential mechanisms underlying fibrogenesis were investigated by exposing hepatic stellate cells (HSCs) to transforming growth factor- $\beta$ (TGF- $\beta$ ), which is a known inducer of myofibroblastic transformation of HSCs. Briefly, a rat model of liver fibrosis was created by administering intraperitoneal injections of $\mathrm{CCl}_{4}$. Furthermore, HSC-T6 cells were stimulated with increasing doses of recombinant TGF- $\beta$ over $24 \mathrm{~h}$. Hepatic fibrosis gradually increased following $\mathrm{CCl}_{4}$ administration in vivo. Western blotting and immunohistochemistry demonstrated that fibronectin ( $\mathrm{FN}), \mathrm{TGF}-\beta$ and $\alpha$-smooth muscle actin (SMA) expression was increased following $\mathrm{CCl}_{4}$ injection, and the maximum expression levels were observed at 8 weeks. Once $\mathrm{CCl}_{4}$ treatment had been terminated, the expression levels of FN, TGF- $\beta$ and $\alpha$-SMA progressively declined to near baseline levels. Western blotting and quantitative polymerase chain reaction demonstrated that $\mathrm{FN}$ expression was gradually increased in response to TGF- $\beta$-stimulation of HSCs; maximum expression was achieved $12 \mathrm{~h}$ post-treatment $(\mathrm{P}<0.01$ vs. the baseline). In conclusion, these findings indicated that FN expression is an early and progressive event that occurs during liver fibrogenesis in vivo and in vitro.
\end{abstract}

Correspondence to: Professor Cheng-Hong Yin, Department of Internal Medicine, Beijing Obstetrics and Gynecology Hospital, Capital Medical University, 251 Yaojiayuan Road, Chaoyang, Beijing 100026, P.R. China

E-mail: modscn@126.com

${ }^{*}$ Contributed equally

Key words: fibronectin, liver fibrosis, myofibroblast, transforming growth factor- $\beta$

\section{Introduction}

Liver fibrosis results from dysregulation of the normal healing process and scar formation, and is a common and potentially severe consequence of virtually all chronic liver diseases (1). Diseases that may lead to liver fibrosis include: Viral and autoimmune hepatitis, drug injury, iron deposition, alcohol consumption and biliary obstruction.

Fibronectin (FN), which is produced by hepatic stellate cells (HSCs), is a multifunctional glycoprotein and extracellular matrix (ECM) component that is present in the cell membrane and cytoplasm $(2,3)$. FN is required in vitro for collagen matrix assembly, and can be used to support other matrix proteins (4-6). In addition, $\mathrm{FN}$ is associated with cell cycle progression, participates in cell adhesion and proliferation, and has an important role in fibrotic progression (7). Although collagen is the main ECM component of fibrotic tissue, excessive FN deposition occurs prior to collagen deposition. Increased expression of the FN isoforms EIIIA and EIIIB occurs during wound healing and tissue repair. These tissue-remodeling processes are associated with liver fibrogenesis, and the expression of these isoforms is often considered an important indicator of ECM accumulation (8-10). Kawelke et al (11) reported that FN protects against excessive liver fibrosis by modulating stellate cell availability and the responsiveness of stellate cells to active transforming growth factor- $\beta$ (TGF- $\beta$ ). In addition, Kawelke et al (11) demonstrated that loss of FN expression leads to increased stellate cell activation at baseline and following TGF- $\beta$ stimulation. Altrock et al (12) reported that interference in collagen deposition, via FN matrix formation inhibitors, decreased fibrosis and improved liver function.

Since FN appears to have an important role in liver fibrogenesis, FN expression may be considered a critical factor mediating the long-term consequences of several chronic liver diseases. Therefore, the present study aimed to determine FN expression patterns during hepatic fibrogenesis using in vitro and in vivo models. The former was conducted with HSCs, which were stimulated with TGF- $\beta$, and the process of fibrogenesis of these cells mimicked acute hepatitis; the latter model was the $\mathrm{CCl} 4$ rat model, used to mimic the process of chronic liver injury, such as chronic hepatitis. 


\section{Materials and methods}

Animals. A total of 50 healthy male Wistar rats (age, 6-8 weeks; weight, $180-200 \mathrm{~g}$ ) were obtained from the Laboratory Animal Center of the Academy of Military Medical Sciences (Beijing, China). The rats were housed in a temperature- and humidity-controlled facility under a $12 \mathrm{~h}$ light-dark cycle, and were given ad libitum access to a standard laboratory diet and tap water. The experimental procedures and ethical requirements of the present study conformed to the Laboratory Animal Management Regulations of the People's Republic of China. All experimental procedures were approved by the Animal Experimental Committee of Beijing Friendship Hospital affiliated with Capital Medical University (Beijing, China).

Carbon tetrachloride $\left(\mathrm{CCl}_{4}\right)$-induced liver fibrosis rat model and sample collection. The 50 rats were randomly divided into the normal control group $(n=6)$ and the liver fibrosis model group $(\mathrm{n}=44)$. The liver fibrosis model group received intraperitoneal injections of $0.15 \mathrm{ml} / 100 \mathrm{~g} 50 \% \mathrm{CCl}_{4}$ in olive oil (5:5, v/v) twice weekly for eight weeks. Rats in the normal control group received intraperitoneal injections of the same volume of physiological saline over the same period. Reversal of liver fibrosis was investigated for 4 weeks after the final intraperitoneal injection. Rats were sacrificed at 2, 4, 6, 8, 10 and 12 weeks. Seven rats were sacrificed at each time point. Two rats succumbed without investigator intervention during week 12. All rats from the normal group were sacrificed during week 8 .

All rats were euthanized under anesthesia using 1\% sodium pentobarbital $(50 \mathrm{mg} / \mathrm{kg}$, i.p). Blood samples were collected for liver function tests. In addition, liver specimens were collected, divided into three parts and subjected to the following analyses: i) mRNA extraction using TRIzol for reverse transcription-quantitative polymerase chain reaction (RT-qPCR) analyses; ii) protein expression analysis of fibrotic indices using western blotting; and iii) histological and immunohistochemical analyses.

Cell culture. The HSC-T6 immortalized rat cell line (Tumor Cell Bank of Chinese Academy of Medical Sciences, Beijing, China) was cultured in Dulbecco's modified Eagle's medium (Gibco; Thermo Fisher Scientific, Inc., Waltham, MA, USA) supplemented with 10\% (v/v) fetal bovine serum (FBS; Gibco; Thermo Fisher Scientific, Inc.), $100 \mathrm{IU} / \mathrm{ml}$ penicillin and $100 \mu \mathrm{g} / \mathrm{ml}$ streptomycin (Beijing Suolaibao Biotechnology Co., Ltd., Beijing, China). Cells were incubated at $37^{\circ} \mathrm{C}$ in a humidified atmosphere containing $5 \% \mathrm{CO}_{2}$. All experiments were carried out $24 \mathrm{~h}$ after the cells were seeded.

Cells were divided into two groups: The control group and the transforming growth factor (TGF)- $\beta$ group. Recombinant human TGF- $\beta$ (Sigma-Aldrich; Merck Millipore, Darmstadt, Germany) was used, since it is a major fibrogenic mediator in the liver $(13,14)$. TGF- $\beta$ was administered to the cultured cells at $0,1,2,5,10$ and $20 \mathrm{ng} / \mathrm{ml}$ for $0,1,3,6,12,24$ and $48 \mathrm{~h}$. Cells were exposed to starvation conditions using FBS-free medium for $24 \mathrm{~h}$ prior to treatment with recombinant human TGF- $\beta$.

FN immunofluorescence assay. Cells were plated at a density of $3 \times 10^{5}$ cells/well in six-well plates, and were allowed to adhere overnight. The cells were then cultured in serum-free medium for an additional $24 \mathrm{~h}$ at $37^{\circ} \mathrm{C}$. Subsequently, cells were rinsed in phosphate-buffered saline ( $3 \times 10 \mathrm{~min})$, and were fixed in $4 \%$ paraformaldehyde $\left(40 \mathrm{~min}, 37^{\circ} \mathrm{C}\right)$ and $3 \% \mathrm{H}_{2} \mathrm{O}_{2}\left(30 \mathrm{~min}, 37^{\circ} \mathrm{C}\right)$. Following fixation, cells were blocked with $1 \%$ FBS (40 min, $37^{\circ} \mathrm{C}$ ) and were incubated overnight at $4^{\circ} \mathrm{C}$ with rabbit anti-mouse elastin primary antibody (FN; 1:100; sc-9068; Santa Cruz Biotechnology, Inc., Dallas, TX, USA). Goat anti-rabbit fluorescein isothiocyanate probes (1:200; bs-0295G-FITC; BIOSS, Beijing, China) were used as secondary antibodies at $37^{\circ} \mathrm{C}$ for $1 \mathrm{~h}$. The cell nuclei were stained using 4',6-diamidino-2-phenylindole (Santa Cruz Biotechnology, Inc.). Immunofluorescence was analyzed using a fluorescence microscope. Cells incubated with normal rabbit serum instead of the primary antibody served as a negative control.

Liver function test. Blood samples were centrifuged at $1,200 \mathrm{x} \mathrm{g}$ for $5 \mathrm{~min}$ at $4^{\circ} \mathrm{C}$ to separate serum from the blood. Serum aspartate transaminase (AST) and alanine transaminase (ALT) (15) activities were determined by the Clinical Laboratory (Beijing Friendship Hospital, Beijing, China).

$R N A$ extraction and $R T-q P C R$. Total RNA was extracted from frozen liver samples or cultured cells using TRIzol ${ }^{\circledR}$ (Invitrogen; Thermo Fisher Scientific, Inc.) according to the manufacturer's protocol. RT was performed using random primers, Moloney Murine Leukemia Virus Reverse Transcriptase and RNase inhibitor (Fermentas; Thermo Fisher Scientific, Inc.). The expression levels of all transcripts were normalized to the expression of the housekeeping gene, glyceraldehyde 3-phosphate dehydrogenase (GAPDH), in the same sample. PCR was performed using Power SYBR Green PCR Master Mix (Applied Biosystems; Thermo Fisher Scientific, Inc.) and an ABI 7500 platform (Applied Biosystems; Thermo Fisher Scientific, Inc.). RNase-free DNase (Promega Corporation, Madison, WI, USA) was used to eliminate the contamination of genomic DNA. The first cDNA strand was synthesized by the RT reaction in a reaction mixture of $20 \mu \mathrm{l}$ containing $4 \mu \mathrm{l} \mathrm{MgCl}_{2}, 3 \mu \mathrm{l}$ 10X RT buffer, $2 \mu \mathrm{l}$ dNTP mixture, $0.5 \mu \mathrm{l}$ recombinant RNase inhibitor, $0.6 \mu \mathrm{l}$ AMV reverse transcriptase, $1 \mu \mathrm{l}$ oligo dT-Adaptor primer and $5 \mu \mathrm{g}$ RNA sample. The RT reaction product was then used for the amplification of cDNA with the SYBR Master Mix reaction system (total, $10 \mu \mathrm{l}$ ) including $1 \mu \mathrm{l}$ upstream primers, $1 \mu \mathrm{l}$ downstream primers, $1 \mu \mathrm{l} \mathrm{cDNA}$ and $7 \mu \mathrm{l}$ diethylpyrocarbonate-treated water. PCR was conducted as follows: Initial denaturation at $95^{\circ} \mathrm{C}$ for $10 \mathrm{~min}, 40$ cycles at $95^{\circ} \mathrm{C}$ for $15 \mathrm{sec}$ and $64^{\circ} \mathrm{C}$ for $30 \mathrm{sec}$, followed by $95^{\circ} \mathrm{C}$ for $15 \mathrm{sec}, 60^{\circ} \mathrm{C}$ for $1 \mathrm{~min}$, $95^{\circ} \mathrm{C}$ for $15 \mathrm{sec}$ and a final extension step at $60^{\circ} \mathrm{C}$ for $15 \mathrm{sec}$. Data were analyzed according to the $2^{-\Delta \Delta \mathrm{C} q}$ method, as described by Livak and Schmittgen (16). The following primer pairs were used: FN, forward 5'-CCAGCCTACGGATGACTC-3', reverse 5'-AATGACCACTGCCAAAGC-3'; and GAPDH, forward 5'-GGCACAGTCAAGGCTGAGAATG-3', and reverse 5'-ATG GTGGTGAAGACGCCAGTA-3' [Sangon Biotech (Shanghai) Co., Ltd., Shanghai, China].

Western blot analysis. Liver tissues and cultured HSCs were homogenized in radioimmunoprecipitation assay buffer and were centrifuged as previously described (17). The supernatants were considered whole-cell lysates. Total protein concentration was determined using a Bicinchoninc Acid Protein Assay kit 
A
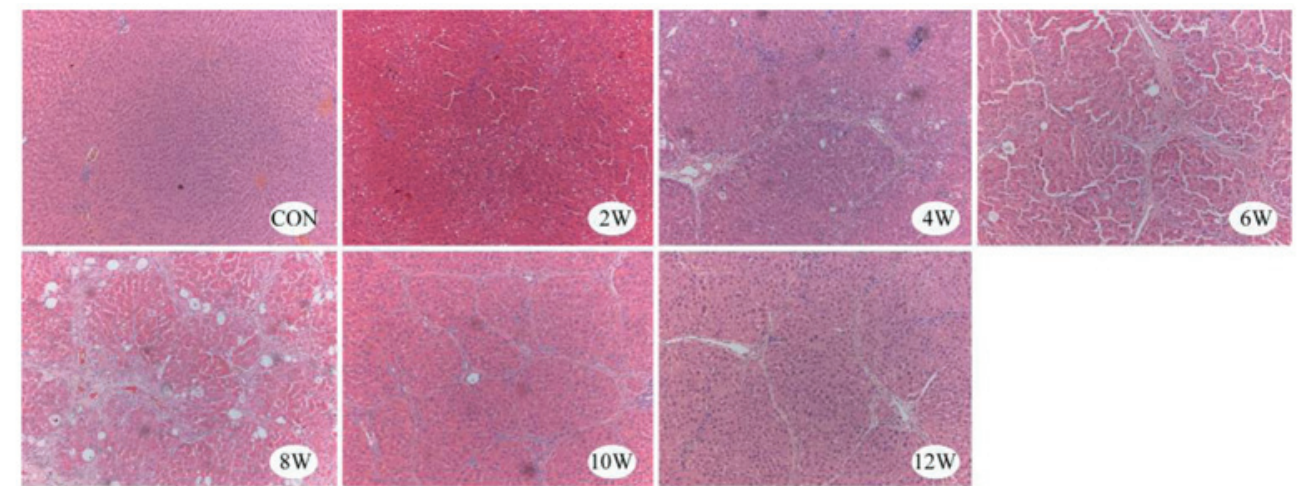

B
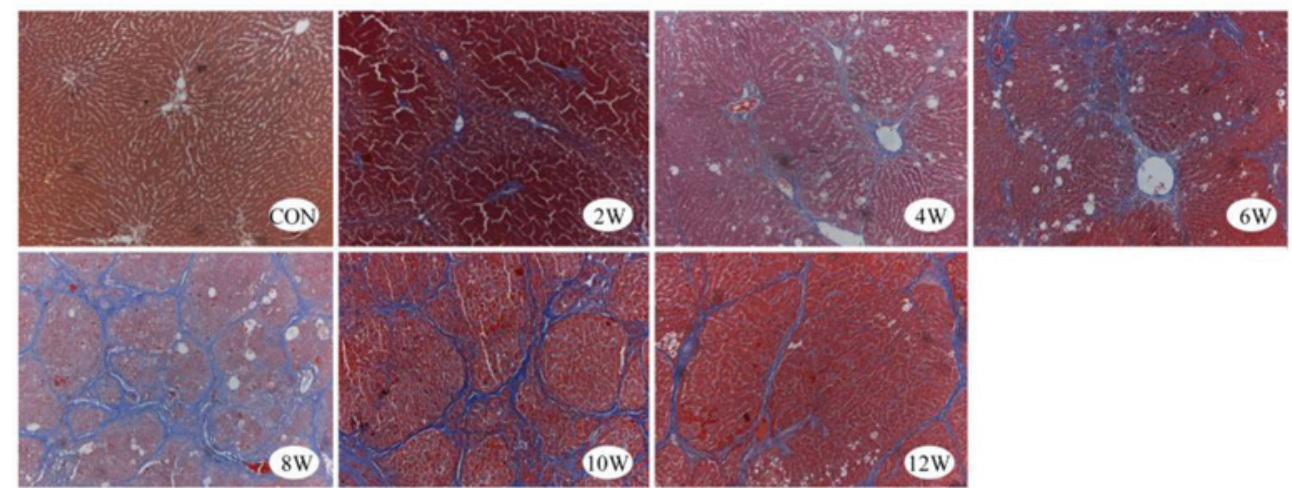

Figure 1. Representative microscopic images of liver sections from control and carbon tetrachloride-treated rats. Tissues were stained for collagen deposition with (A) hematoxylin and eosin, and (B) Masson's trichrome. Original magnification, x100. CON, control.
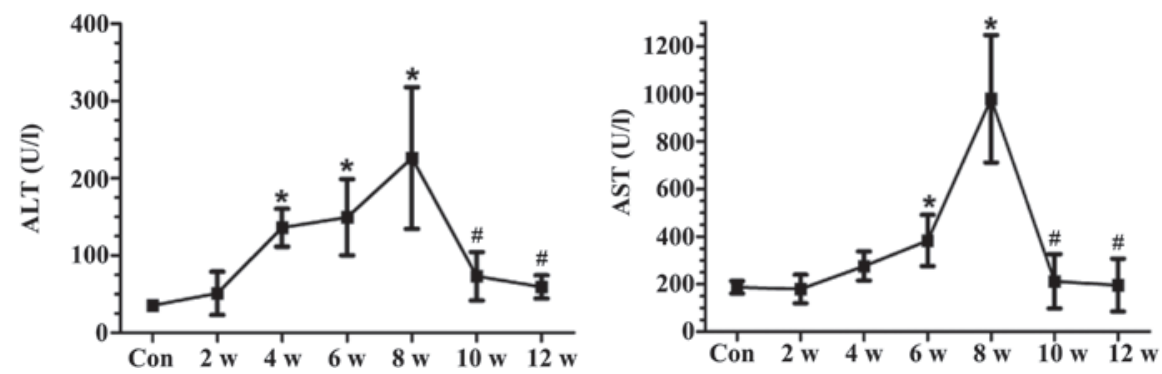

Figure 2. Serum ALT and AST activities of carbon tetrachloride-treated and control rats. Data are presented as the mean \pm standard deviation of experiments performed in duplicate $(\mathrm{n}=6) .{ }^{*} \mathrm{P}<0.05$ vs. the Con group; ${ }^{\prime \prime} \mathrm{P}<0.05$ vs. the $8 \mathrm{w}$ group. ALT, alanine transaminase; AST, aspartate transaminase; Con, control.

(Pierce; Thermo Fisher Scientific, Inc.). Proteins ( $\sim 80 \mu \mathrm{g})$ were separated by $8 \%$ sodium dodecyl sulfate-polyacrylamide gel electrophoresis and were transferred to polyvinylidene fluoride membranes by electroblotting. Subsequently, the membranes were incubated for $3 \mathrm{~h}$ with $5 \%$ non-fat dry milk at $37^{\circ} \mathrm{C}$, followed by an overnight incubation at $4^{\circ} \mathrm{C}$ with mouse anti-FN polyclonal antibody (1:600; sc-8422; Santa Cruz Biotechnology, Inc.), rabbit anti-TGF- $\beta$ antibody (1:800; ab92486; Abcam, Cambridge, UK), rabbit anti- $\alpha$-smooth muscle actin ( $\alpha$-SMA) antibody (1:800; ab5694; Abcam) and mouse anti- $\beta$-actin monoclonal antibody (1:800; ab8226; Abcam). Following the overnight incubation, membranes were incubated for $1 \mathrm{~h}$ at $37^{\circ} \mathrm{C}$ with peroxidase-conjugated goat anti-mouse secondary antibodies (1:6,000 in Tris-buffered saline containing 1\% Tween; sc-2005; Santa Cruz Biotechnology, Inc.). Enhanced chemiluminescence (EMD Millipore, Billerica, MA, USA) was used to detect immunoreactive bands. Finally, densitometric analysis of the bands was performed using Image Lab software, version 4.0 (Bio-Rad Laboratories, Inc., Hercules, CA, USA).
Histopathology and immunohistochemistry. Liver samples were fixed in $4 \%$ paraformaldehyde, embedded in paraffin and sectioned at $3 \mu \mathrm{m}$. The tissue sections were then stained with hematoxylin and eosin (H\&E) or Masson's trichrome, and were examined for changes in liver pathology. The histopathological scores for fibrosis were evaluated according to previously published criteria (18), as follows: 0, Normal liver; 1, increased collagen matrix accumulation without septa formation (small stellate expansions of the portal fields); 2 , formation of incomplete septa from the portal tract to the central vein (septa that do not interconnect with each other); 3 , complete but thin septa interconnecting with each other to divide the parenchyma into separate fragments; and 4, similar to grade 3, except for the presence of thick septa (complete cirrhosis).

Immunohistochemical analysis of paraffin-embedded sections was performed using a microwave-based antigen retrieval method, as described previously (19), and antibodies against FN were used (mouse polyclonal; 1:100; sc-8422; Santa Cruz Biotechnology, Inc.). In brief, histological sections were 
heated for $60 \mathrm{~min}$ at $60^{\circ} \mathrm{C}$, deparaffinized with xylene and rinsed in a reducing gradient of alcohol. Subsequently, antigens were retrieved with citrate buffer in a microwave oven. Subsequent to treatment with hydrogen peroxide at $37^{\circ} \mathrm{C}$ for 30 min to block endogenous peroxidase activity, the sections were incubated with the primary antibody overnight at $4^{\circ} \mathrm{C}$ and then incubated with the secondary antibody (PV-9002; OriGene Technologies, Inc., Beijing, China) for $30 \mathrm{~min}$ at room temperature. Finally stained sections were developed using diaminobenzidine and were counterstained with hematoxylin and a BX43 optical microscope (Olympus Corporation, Tokyo, Japan) was used for analysis. FN expression was analyzed using a quantitative image analysis system (Image-Pro Plus 6.0; Media Cybernetics Inc., Rockville, MD, USA). Briefly, 10 fields were randomly selected from each section and positive signals within the section were highlighted, measured and expressed as a percentage of the positive areas within the entirety of the examined liver tissue.

Statistical analysis. Analyses were performed using SPSS software (SPSS version 17.0; SPSS Inc., Chicago, IL, USA), and the differences between multiple groups were evaluated using one-way analysis of variance and the least significant difference test was used for multiple comparisons. Results are presented as the mean \pm standard deviation and experiments were repeated 6 times. $\mathrm{P}<0.05$ was considered to indicate a statistically significant difference.

\section{Results}

Liver pathology in $\mathrm{CCl}_{4}$-treated mice. In the liver samples of the control group, normal lobular architecture was observed with hepatic cords radiating from the central veins, and the absence of regenerated collagen fibers, as detected by H\&E and Masson's trichrome staining. Conversely, liver samples from the experimental group (2-12 weeks) exhibited severe fibrosis. Morphological alterations in the experimental group included thick fibrotic septa, fatty degeneration, enlarged hepatocytes with nodular arrangement, focal inflammatory changes, thickened vessel walls and early capillarization (Fig. 1).

The hepatic lobule structure persisted beyond 4 weeks; however, in the $\mathrm{CCl}_{4}$ treatment group the appearance of the hepatic lobules became disorganized, and were characterized by fibrous septa, severe fatty degeneration, hydropic degeneration and focal necrosis. After 6 and 8 weeks of $\mathrm{CCl}_{4}$ treatment, pseudolobules, and inflammatory cell infiltration into the portal areas and fibrous septa were observed. At 12 weeks (or 4 weeks after the final $\mathrm{CCl}_{4}$ injection), fibrous septa began to attenuate or exhibit discontinuous shapes, with some of the fibrous septa becoming barely visible (Fig. 1).

Changes in serum indices of liver function. Treatment with $\mathrm{CCl}_{4}$ (2-8 weeks) resulted in a significant elevation in AST and ALT levels. However, at 10 weeks (2 weeks after the final $\mathrm{CCl}_{4}$ injection), AST and ALT levels were markedly lower compared with those measured at 8 weeks (Fig. 2).

$\alpha$-SMA and TGF- $\beta$ protein expression in vivo. $\alpha$-SMA expression in HSCs reflects myofibroblast-like cell activation, has been directly linked to experimental liver fibrogenesis, and is indirectly associated with fibrosis in chronic human liver disease (20).
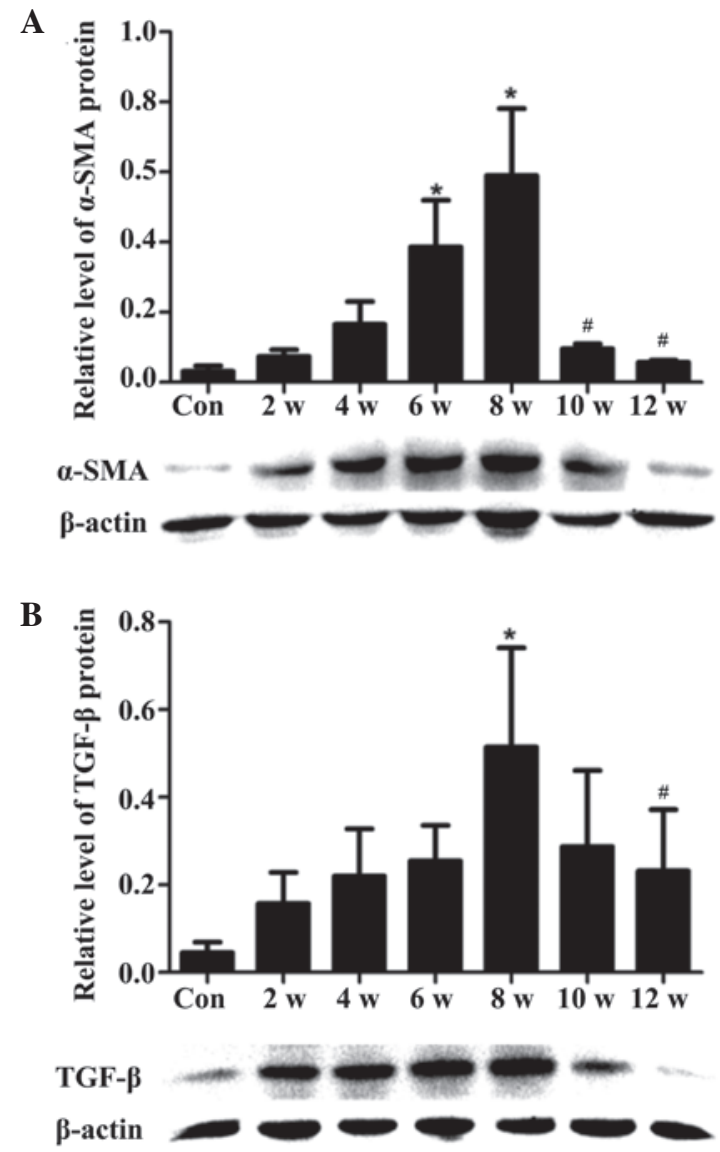

Figure 3. Protein expression levels of $\alpha$-SMA and TGF- $\beta$ in carbon tetrachloride-treated and control rats. (A) $\alpha$-SMA and (B) TGF- $\beta$ protein expression levels were detected in the liver by western blotting. Data are presented as the mean \pm standard deviation from 6 rats. ${ }^{*} \mathrm{P}<0.05$ vs. the Con group; ${ }^{*} \mathrm{P}<0.05$ vs. the $8 \mathrm{w}$ group. Con, control; $\alpha$-SMA, $\alpha$-smooth muscle actin; TGF- $\beta$, transforming growth factor- $\beta$.

The expression levels of $\alpha$-SMA were increased in the $\mathrm{CCl}_{4}$ treatment group compared with in the control group. However, when $\mathrm{CCl}_{4}$ treatment ceased, protein expression returned to baseline levels (Fig. 3A). In addition, the expression levels of TGF- $\beta$ were elevated in the $\mathrm{CCl}_{4}$ treatment group (2-8 weeks), and this increase corresponded with the degree of liver fibrosis (Fig. 3B).

In vivo location, and hepatic $m R N A$ and protein expression levels of FN during hepatic fibrogenesis. Markedly increased FN staining was detected in hepatocytes, sinusoidal areas, extracellular spaces, and portal and central areas in the experimental group tissues compared with in the control tissues, as determined by immunohistochemical staining of FN in liver sections. FN expression increased with increasing fibrosis, and peaked during week 8 . However, after week 8 and the discontinuation of $\mathrm{CCl}_{4}$ treatment, $\mathrm{FN}$ staining gradually decreased (Fig. 4A). The criterion used to assess FN positivity was yellow or brown staining in the cell membrane or mesenchyme.

The protein expression levels of $\mathrm{FN}$ in $\mathrm{CCl}_{4}$-injured liver tissues gradually increased during the course of liver fibrogenesis. As detected by western blotting, FN expression reached its maximal point during week 8 , after which expression gradually decreased (Fig. 4B). The mRNA expression levels of FN rapidly increased to a maximum level during the first 2 weeks. After the first 2 weeks, expression gradually fell (Fig. 4C). 

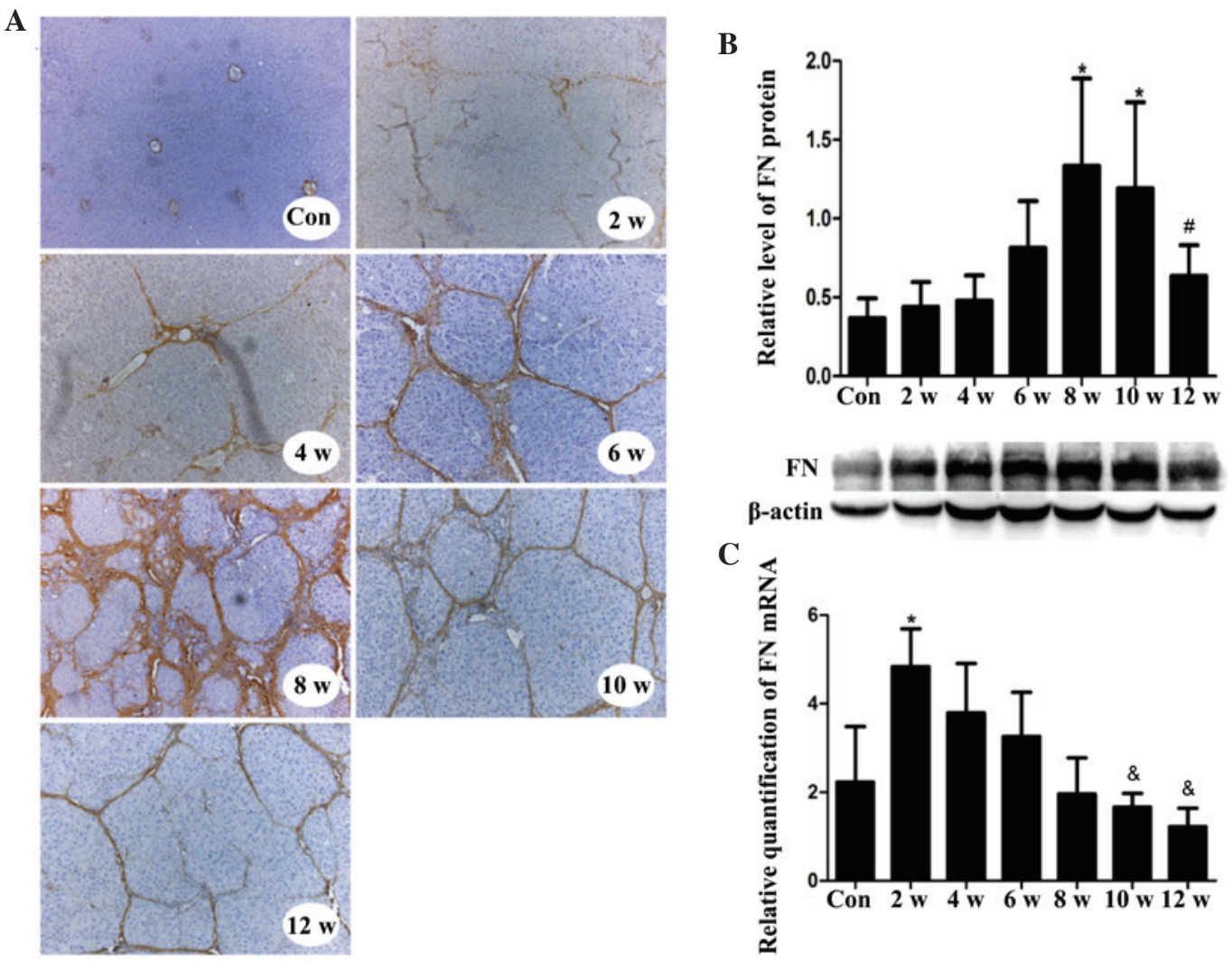

Figure 4. In vivo $\mathrm{FN}$ mRNA and protein expression in $\mathrm{CCl}_{4}$-treated and control rats, and the location of $\mathrm{FN}$ in liver tissue during the course of hepatic fibrogenesis. (A) FN staining in liver sections from control and $\mathrm{CCl}_{4}$-treated rats. One representative image from each time point is shown. Original magnification, x200. (B) Protein expression levels of FN in the liver, as detected by western blotting. (C) mRNA expression levels of FN relative to glyceraldehyde 3-phosphate dehydrogenase, as detected by quantitative polymerase chain reaction. Each sample was analyzed in duplicate ( $\mathrm{n}=6 / \mathrm{group}$ ). Data are presented as the mean \pm standard deviation. ${ }^{*} \mathrm{P}<0.05$ vs. the Con group; ${ }^{*} \mathrm{P}<0.05 \mathrm{vs}$. the $8 \mathrm{w}$ group; ${ }^{\&} \mathrm{P}<0.05$ vs. the $2 \mathrm{w}$ group. Con, control; CCl ${ }_{4}$, carbon tetrachloride; $\mathrm{FN}$, fibronectin.

In vitro location, and $m R N A$ and protein expression levels of FN in HSC-T6 cells. Immunofluorescence assays demonstrated that FN was primarily located in the cytoplasm of HSC-T6 cells (Fig. 5A). TGF- $\beta$ stimulation upregulated the mRNA and protein expression levels of FN in HSC-T6 cells in a dose- and time-dependent manner (Fig. 5B-E).

\section{Discussion}

Liver fibrosis is a category of interest in liver disease research due to its importance in the natural history of chronic liver diseases. Previous studies have revealed that hepatic fibrogenesis is a dynamic process, and that the capacity for recovery exists from any degree of fibrosis, including established cirrhosis $(21,22)$.

The present study induced hepatic fibrosis in male Wistar rats via intraperitoneal injections of $\mathrm{CCl}_{4}$. This regimen induced major fibrosis, which regressed following the discontinuation of $\mathrm{CCl}_{4}$ treatment. Decreased serum ALT and AST activities, and TGF- $\beta$ and $\alpha$-SMA protein levels were detected following the discontinuation of $\mathrm{CCl}_{4}$ treatment, mimicking the clinically observed expression patterns.

The progression of liver fibrosis is characterized by the gradual accumulation of ECM proteins in injured tissue, and HSCs have a crucial role in this fibrotic response (23). Upon liver injury, quiescent HSCs are activated and transdifferentiate into myofibroblast-like cells. These myofibroblast-like cells are characterized by increased proliferation and excessive deposition of ECM proteins (24). In addition, activated HSCs are able to upregulate the expression of cytoskeletal proteins, including $\alpha$-SMA. Therefore, $\alpha$-SMA is considered a marker of HSC activation, which may reflect the degree of liver fibrosis $(25,26)$. Alterations to the hepatic architecture occur due to the combined increase in cytoskeletal protein synthesis and the inability to break down these proteins, resulting in liver fibrosis and, eventually, cirrhosis (27). The results of the present study suggested that HSC activation indirectly indicated the level of ECM deposition and the degree of liver fibrosis. In the present study, $\alpha$-SMA expression was detected at various time points following $\mathrm{CCl}_{4}$ injection, and the results demonstrated that $\alpha$-SMA expression increased in response to $\mathrm{CCl}_{4}$ treatment, in a time-dependent manner. However, when $\mathrm{CCl}_{4}$ treatment was terminated, $\alpha$-SMA protein expression returned to baseline. These results suggested that liver fibrosis can be reversed.

Increasing evidence has indicated that TGF- $\beta$ is a key mediator of liver fibrosis $(14,28,29)$. Myofibroblast differentiation of HSCs is induced by TGF- $\beta$, and TGF- $\beta$ induction results in increased ECM protein production (30). Thus, it is suggested that TGF- $\beta$ serves an important role in morphogenesis, proliferation and differentiation of cells, and is good for cell repair. With fibrosis of the liver, the expression of TGF- $\beta$ will increase in order to repair the damaged liver tissue. Thus, TGF- $\beta$ expression is increased in damaged liver compared with the normal liver.

FN is a non-collagenous glycoprotein with several functions. FN is produced and secreted by fibroblasts, 

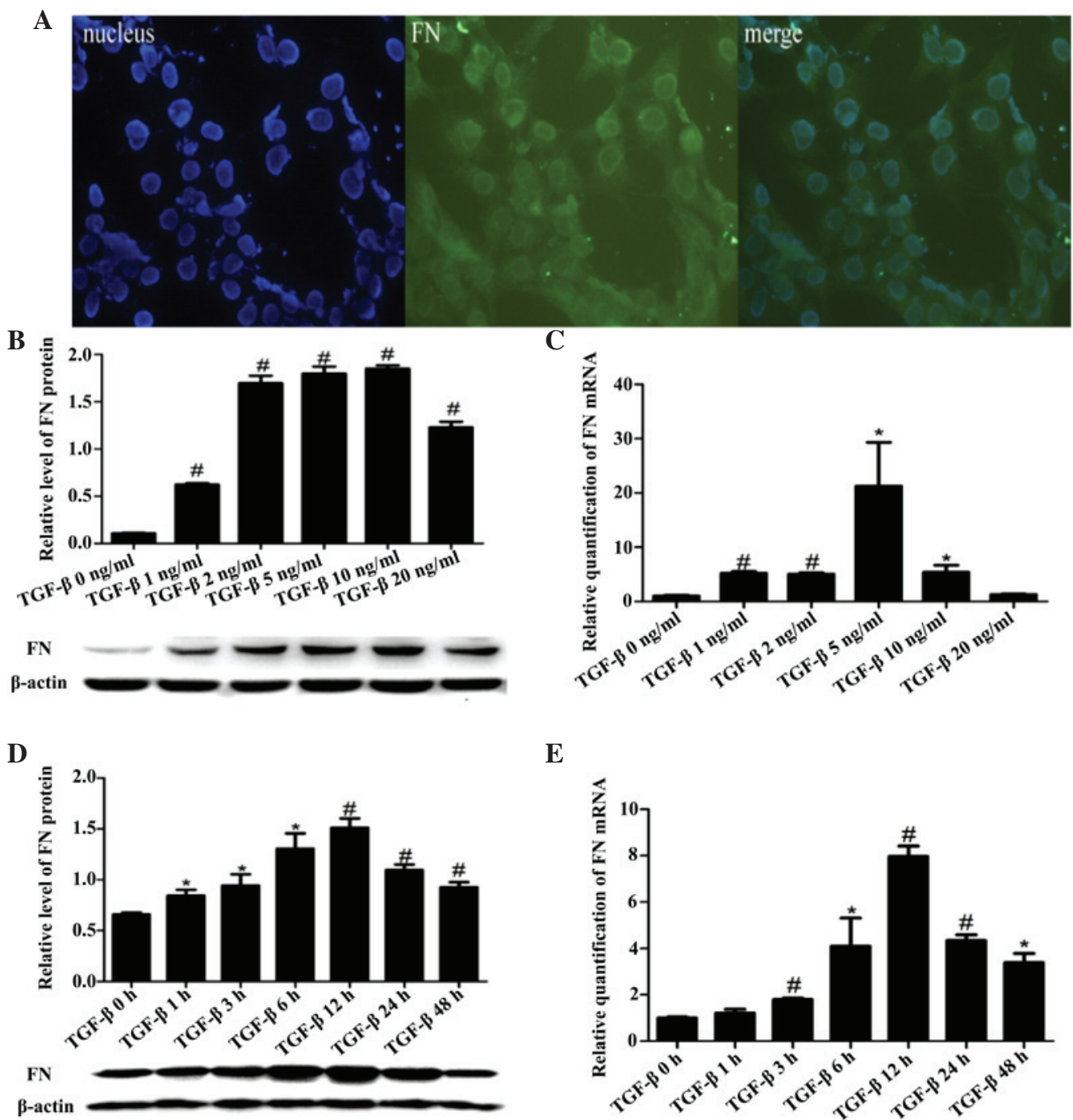

$\mathbf{E}$

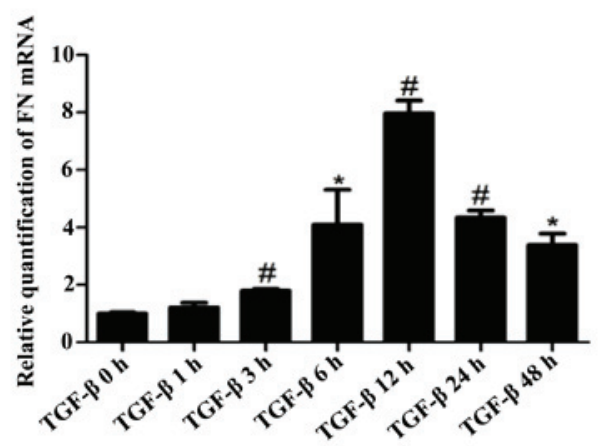

Figure 5. FN location, and mRNA and protein expression in HSC-T6 cells. (A) FN immunofluorescence localization in HSC-T6 cells. Blue, nucleus (left); green, target protein (middle); merged green and blue image (right). Magnification, x40. (B) Protein expression levels of FN in the HSC-T6 cells, as detected by western blotting. (C) mRNA expression levels of FN in HSC-T6 cells, as detected by RT-qPCR. FN expression was normalized to GAPDH (internal control). (B and C) Six concentrations of TGF- $\beta(0,1,2,5,10$ and $20 \mathrm{ng} / \mathrm{ml}$ ) were assayed. (D) Protein expression levels of FN in the HSC-T6 cells, as detected by western blotting. (E) mRNA expression levels of FN in HSC-T6 cells, as detected by RT-qPCR. FN expression was normalized to GAPDH (internal control). (D and E) Seven time points $(0,1,3,6,12,24$ and $48 \mathrm{~h}$ ) were assayed, and HSC-T6 cells were stimulated with TGF- $\beta$ (5 ng/ml). Data are presented as the mean \pm standard deviation. ${ }^{\prime} \mathrm{P}<0.05$ vs. the Con group; ${ }^{\prime} \mathrm{P}<0.01$ vs. the Con group. Con, control; HSC, hepatic stellate cells; FN, fibronectin; TGF- $\beta$, transforming growth factor- $\beta$.

endothelial cells, macrophages and hepatocytes in vivo (31), and its expression is closely associated with hepatic fibrosis, cellular damage, differentiation and repair. In the present study, $\mathrm{FN}$ expression increased with increasing $\mathrm{CCl}_{4}$ levels, and decreased when $\mathrm{CCl}_{4}$ injections ceased. Furthermore, $\mathrm{FN}$ expression levels were associated with the degree of hepatic fibrosis; however, it was also confirmed that liver fibrosis could be reversed. The present study also demonstrated that FN expression varied during the process of fibrogenesis according to the type of hepatitis (acute or chronic).

In acute hepatitis, fibroblasts proliferate and FN levels increase after liver injury $(32,33)$. Conversely, in chronic hepatitis, FN levels increase due to fibrous tissue hyperplasia; however, due to significant FN deposition in the fibrous tissue, the FN content of the liver appears to fall after the formation of liver fibrosis (34). Nevertheless, the total deposition of FN consistently reflects the degree of liver fibrosis and the degree of ECM deposition, and is an important marker of hepatic fibrosis.

The in vivo experiments conducted in the present study were designed to simulate chronic hepatitis, and the results indicated that the mRNA expression levels of FN peaked as early as at 2 weeks. The time lag between FN mRNA expression and the expression of the corresponding protein may be related to the time required for FN synthesis in the liver. The detected upregulated mRNA levels may represent activation of the promoter or enhancer, or of upstream transcription factors; however, whereas protein levels are usually coupled to the biological function of the proteins themselves, this is not always true for the corresponding mRNA levels.

The in vitro experiments conducted in the present study were designed to more closely represent the conditions present during acute hepatitis. The results indicated that FN mRNA 
expression corresponded with FN protein expression, with peak mRNA and protein expression values observed in response to the same concentration and duration of TGF- $\beta$ stimulation. The above results indicate that the protein expression may not be consistent with the corresponding RNA expression in the chronic hepatitis model, however, in the acute hepatitis model, the expression of these two indexes tended to be consistent.

In conclusion, the present study confirmed the reversibility of liver fibrosis. This was true even after the establishment of cirrhosis. The results indicated that FN may have an early and critical role during the process of liver fibrogenesis. The in vivo and in vitro models exhibited marked differences in $\mathrm{FN}$ expression, and these differences may closely resemble those between chronic and acute human hepatitis.

\section{Acknowledgements}

The present study was funded by the National Natural Science Foundation of China (grant no. 81300334) and the WBE Liver Fibrosis Foundation (grant no. CFHPC20120145). The authors would like to thank Medjaden Bioscience Limited for assisting in the preparation of this manuscript.

\section{References}

1. Cong M, Liu T, Wang P, Fan X, Yang A, Bai Y, Peng Z, Wu P, Tong $\mathrm{X}$, Chen $\mathrm{J}$, et al: Antifibrotic effects of a recombinant adeno-associated virus carrying small interfering RNA targeting TIMP-1 in rat liver fibrosis. Am J Pathol 182: 1607-1616, 2013.

2. Xu G, Niki T, Virtanen I, Rogiers V, De Bleser P and Geerts A: Gene expression and synthesis of fibronectin isoforms in rat hepatic stellate cells. Comparison with liver parenchymal cells and skin fibroblasts. J Pathol 183: 90-98, 1997.

3. Matsui S, Takahashi T, Oyanagi Y, Takahashi S, Boku S, Takahashi K, Furukawa K, Arai F and Asakura H: Expression, localization and alternative splicing pattern of fibronectin messenger RNA in fibrotic human liver and hepatocellular carcinoma. J Hepatol 27: 843-853, 1997.

4. Sottile J and Hocking DC: Fibronectin polymerization regulates the composition and stability of extracellular matrix fibrils and cell-matrix adhesions. MolBiol Cell 13: 3546-3559, 2002.

5. Velling T, Risteli J, Wennerberg K, Mosher DF and Johansson S: Polymerization of type I and III collagens is dependent on fibronectin and enhanced by integrins alpha 11beta 1 and alpha 2 beta 1. J Biol Chem 277: 37377-37381, 2002.

6. Roeb E and Matern S: Fibronectin-a key substance in pathogenesis of liver cirrhosis? Leber Magen Darm 23: 239-242, 1993 (In German).

7. Manabe R, Oh-e N and Sekiguchi K: Alternatively spliced EDA segment regulates fibronectin-dependent cell cycle progression and mitogenic signal transduction. J Biol Chem 274: 5919-5924, 1999.

8. Krzyzanowska-Gołab D, Lemańska-Perek A and Katnik-Prastowska I: Fibronectin as an active component of the extracellular matrix. Postepy Hig Med Dosw (Online) 61 655-663, 2007 (In Polish).

9. Leite AR, Corrêa-Giannella ML, Dagli ML, Fortes MA, Vegas VM and Giannella-Neto D: Fibronectin and laminin induce expression of islet cell markers in hepatic oval cells in culture. Cell Tissue Res 327: 529-537, 2007.

10. Mòdol T, Brice N, Ruiz de Galarreta R, García Garzón A, Iraburu MJ, Martínez-Irujo JJ and López-Zabalza MJ: Fibronectin peptides as potential regulators of hepatic fibrosis through apoptosis of hepatic stellate cells. J Cell Physiol 230: $546-553,2015$

11. Kawelke N, Vasel M, Sens C, Av A, Dooley S and Nakchbandi IA: Fibronectin protects from excessive liver fibrosis by modulating the availability of and responsiveness of stellate cells to active TGF- $\beta$. PLoS One 6: e28181, 2011.

12. Altrock E, Sens C, Wuerfel C, Vasel M, Kawelke N, Dooley S, Sottile J and Nakchbandi IA: Inhibition of fibronectin deposition improves experimental liver fibrosis. J Hepatol 62: 625-633, 2015.
13. Parsons CJ, Takashima M and Rippe RA: Molecular mechanisms of hepatic fibrogenesis. J Gastroenterol Hepatol 22 (Suppl 1): S79-S84, 2007.

14. Inagaki Y and Okazaki I: Emerging insights into Transforming growth factor beta Smad signal in hepatic fibrogenesis. Gut 56: 284-292, 2007.

15. Reitman S and Frankel S: A colorimetric method for the determination of serum glutamic oxalacetic and glutamic pyruvic transaminases. Am J Clin Pathol 28: 56-63, 1957.

16. Livak KJ and Schmittgen TD: Analysis of relative gene expression data using real-time quantitative PCR and the 2(-Delta DeltaC (T)) method. Methods 25: 402-408, 2001.

17. Zhang X, Yang J, Li Y and Liu Y: Both Sp1 and Smad participate in mediating TGF-beta1-induced HGF receptor expression in renal epithelial cells. Am J Physiol Renal Physiol 288: F16-F26, 2005.

18. Ruwart MJ, Wilkinson KF, Rush BD, Vidmar TJ, Peters KM, Henley KS, Appelman HD, Kim KY, Schuppan D and Hahn EG: The integrated value of serum procollagen III peptide over time predicts hepatic hydroxyproline content and stainable collagen in a model of dietary cirrhosis in the rat. Hepatology 10: 801-806, 1989.

19. Lan HY, Mu W, Nikolic-Paterson DJ and Atkins RC: A novel, simple, reliable, and sensitive method for multiple immunoenzyme staining: Use of microwave oven heating to block antibody crossreactivity and retrieve antigens. J Histochem Cytochem 43: 97-102, 1995.

20. Carpino G, Morini S, Ginanni Corradini S, Franchitto A, Merli M, Siciliano M, Gentili F, Onetti Muda A, Berloco P, Rossi M, et al: Alpha-SMA expression in hepatic stellate cells and quantitative analysis of hepatic fibrosis in cirrhosis and in recurrent chronic hepatitis after liver transplantation. Dig Liver Dis 37: 349-356, 2005.

21. Sohrabpour AA, Mohamadnejad M and Malekzadeh R: Review article: The reversibility of cirrhosis. Aliment Pharmacol Ther 36: 824-832, 2012.

22. Brenner DA: Reversibility of liver fibrosis. Gastroenterol Hepatol (N Y) 9: 737-739, 2013

23. Bataller R and Brenner DA: Liver fibrosis. J Clin Invest 115: 209-218, 2005.

24. Foo NP, Lin SH, Lee YH, Wu MJ and Wang YJ: $\alpha$-Lipoic acid inhibits liver fibrosis through the attenuation of ROS-triggered signaling in hepatic stellate cells activated by PDGF and TGF- $\alpha$. Toxicology 282: 39-46, 2011.

25. Friedman SL: Hepatic stellate cells: Protean, multifunctional, and enigmatic cells of the liver. Physiol Rev 88: 125-172, 2008.

26. Bae MA, Rhee SD, Jung WH, Ahn JH, Song BJ and Cheon HG: Selective inhibition of activated stellate cells and protection from carbon tetrachloride-induced liver injury in rats by a new PPARgamma agonist KR62776. Arch Pharm Res 33: 433-442, 2010.

27. Svegliati-Baroni G, De Minicis S and Marzioni M: Hepatic fibrogenesis in response to chronic liver injury: Novel insights on the role of cell-to-cell interaction and transition. Liver Int 28: 1052-1064, 2008.

28. Meindl-Beinker NM and Dooley S: Transforming growth factor-beta and hepatocyte transdifferentiation in liver fibrogenesis. J Gastroenterol Hepatol 23 (Suppl 1): S122-S127, 2008.

29. Arauz J, Zarco N, Segovia J, Shibayama M, Tsutsumi V and Muriel P: Caffeine prevents experimental liver fibrosis by blocking the expression of TGF- $\beta$. Eur J Gastroenterol Hepatol 26: 164-273, 2014.

30. Gressner AM and Weiskirchen R: Modern pathogenetic concepts of liver fibrosis suggest stellate cells and TGF-beta as major players and therapeutic targets. J Cell Mol Med 10: 76-99, 2006.

31. Mosesson MW: Fibrinogen and fibrin and structure and functions. J Thromb Haemost: 3: 1894-1904, 2005.

32. Wielockx B, Lannoy K, Shapiro SD, Itoh T, Itohara S, Vandekerckhove $\mathrm{J}$ and Libert C: Inhibition of matrix metalloproteinases blocks lethal hepatitis and apoptosis induced by tumor necrosis factor and allows safe antitumor therapy. Nat Med 7: 1202-1208, 2001.

33. Leu JI, Crissey MA and Taub R: Massive hepatic apoptosis associated with TGF-beta1 activation after Fas ligand treatment of IGF binding protein-1-deficient mice. J Clin Invest 111: 129-139, 2003.

34. Kandemir O, Polat G, Sahin E, Bagdatoglu O, Camdeviren H and Kaya A: Fibronectin levels in chronic viral hepatitis and response of this protein to interferon therapy. Hepatogastroenterology 51: 811-814, 2004. 